\title{
Sleep-Related Abdominal Muscle Behavior during Partial or Complete Obstructed Breathing in Prepubertal Children ${ }^{1}$
}

\author{
J. P. PRAUD, A. M. D'AlLEST, H. NEDELCOUX, L. CURZI-DASCALOVA, \\ CH. GUILLEMINAULT, ${ }^{2}$ AND $\mathrm{Cl}$. GAULTIER \\ Laboratory of Physiology and CNRS UA 1159, Hospital A. Beclere, 92141 Clamart, France
}

\begin{abstract}
We have evaluated the influence of nonrapid eye movement (NREM), REM sleep, and arousal on abdominal muscle contractions during snoring and/or obstructive apnea in $\mathbf{1 0}$ prepubertal children. All children were known habitual snorers and eight had a sleep apnea index above 10. During stage 3-4 non-REM sleep, nonapneic breathing with snoring was always associated with the presence of expiratory abdominal muscle electromyogram (EMG) discharges. During non-REM sleep apneas, abdominal muscle EMG discharges increased from the beginning to the end of each apnea. Termination of nonREM sleep apnea was marked by an "EEG arousal" in $12 \%$ of the apneic events and by a "movement arousal" in the other $88 \%$. The highest abdominal muscle EMG discharge was always observed during the arousal response. During "phasic" REM sleep, abdominal muscle EMG discharges were absent during both nonapneic breathing (with or without snoring) and obstructive apneas. All REM sleep apneas ended with a "movement arousal," during which abdominal muscle EMG discharges were observed. Thus, abdominal muscle EMG discharges associated with "arousal" were seen independent of the immediately preceding sleep state. (Pediatr Res 26: 347-350, 1989)
\end{abstract}

\section{Abbreviations}

EMG, electromyogram

REM, rapid eye movement

NREM sleep, non-REM sleep

OSAS, obstructive sleep apnea syndrome

$\mathrm{SaO}_{2}$, oxygen arterial saturation

To better understand the pathophysiology of the OSAS, research has often focused on the inspiratory behavior of upper airway and diaphragmatic muscles (1-3). However, the importance of expiratory airway patency and expiratory muscle activity has recently been emphasized. A recruitment of abdominal muscle expiratory activity has been reported in healthy snorers and related to the sleep-induced increase in upper airway resistance (4-6). Furthermore, a tonic (7) and phasic (7-9) recruitment of abdominal muscles during expiration has been shown in adults

Received January 24, 1989; accepted May 12, 1989.

Correspondence J. P. Praud, Hospital A. Beclere, 92141 Clamart, France.

Supported by INSERM (CNAMTS) Grant 87.33605 E. Ch.G. was supported by INSERM during sabbatical leave.

${ }^{1}$ Part of the data has been presented at the $22 \mathrm{nd}$ Annual Meeting of the SEPCR, Antwerp 1987.

${ }^{2}$ Present address: Stanford University Sleep Disorders Center, Stanford, CA 94305 .
$(7,8)$ and children $(9)$ with OSAS. These findings are, however, incomplete because the studies ignored any sleep stage or state relationship (9) or were limited to the NREM sleep period (4-8).

Children with enlarged tonsils and adenoids and/or craniofacial malformations may snore and develop obstructive sleep apnea. We questioned previous suggestions that such children had an expiratory contraction of abdominal muscles during sleep (9) and evaluated the influence of NREM and REM sleep, and of arousal, on abdominal muscle contractions during snoring and/or obstructive apnea.

\section{MATERIALS AND METHODS}

With informed parental consent, we studied 10 prepubertal nonobese children (five girls and five boys), mean age $5.5 \mathrm{y}$ (range 3-7.5 y), all of whom were reported by parents to snore heavily at night. None of the children had CNS malformation at clinical and EEG examinations. Based on nocturnal polygraphic monitoring the patients were classified as "obstructive sleep apneic" $(n=8)$ or "heavy snorer" $(n=2)$. "Heavy snorers" had an apnea index (see definition section) less than 6 during sleep, whereas "obstructive sleep apneic" subjects had an index above 10 (Table 1).

After arriving in the afternoon to adapt to the laboratory conditions, each child spent one night in the laboratory. The normal bedtime and usual sleep routines were maintained. For sleep stage and state determination, EEG $\left(\mathrm{Fp}_{2}-\mathrm{C}_{4}, \mathrm{Fp}_{1}-\mathrm{C}_{3}, \mathrm{C}_{3}-\right.$ $\mathrm{C}_{4}$ of the 10-20 international electrode placement system), electrooculogram (accelerometer), and chin muscle EMG were monitored. Respiration was monitored by 1 ) magnetometer coils (three children) or noncalibrated inductive respiratory plethysmography (Respitrace, Ambulatory Monitoring, Ardsley, NY) (seven children), 2) $\mathrm{SaO}_{2}$ (pulse oximetry, Biox 3700), and 3) airflow determination, derived from buccal and nasal thermistors. One electrocardiographic lead (DII) was also recorded. Finally, we continuously monitored the electrical activity of diaphragmatic and abdominal muscles. This recording was performed from surface electrodes (Physiosystem, Nevilly-Plaisance, France): two electrodes were placed anteriorly on the midaxillary line for diaphragmatic recording within the right eighth intercostal space. Two other electrodes, placed at midpoint between umbilicus and iliac crest, monitored abdominal muscle activity. Raw EMG signals were amplified (Gould Universal amplifier, Gould Inc., Cleveland, $\mathrm{OH}$ ) and filtered with $30-1000 \mathrm{~Hz}$ low and high frequency filters. In four children the abdominal muscle EMG signals were integrated. The integrator (Physiology Department, Paris XI Faculty of Medicine) received the amplified and band-pass filtered signals (Gould Universal amplifier). Signals were first rectified and were then integrated based on a "sample/hold technology" with $100 \mathrm{~ms}$ successive sampling time. Breath sounds were monitored with a microphone built by the 
Table 1. Clinical characteristics and polygraphic results

\begin{tabular}{|c|c|c|c|c|c|c|c|}
\hline Patient & Sex & $\begin{array}{l}\text { Age } \\
(\mathrm{y})\end{array}$ & Diagnosis & $\begin{array}{l}\text { Total sleep } \\
\text { time (min) }\end{array}$ & $\%$ REM sleep & Apnea index & $\begin{array}{c}\text { Lowest measured } \\
\mathrm{SaO}_{2}(\%)\end{array}$ \\
\hline 1 & $\mathrm{~F}$ & 5.5 & Crouzon syndrome & 384 & 19 & 36 & 84 \\
\hline 2 & M & 4.5 & Micrognathia & 312 & 18 & 16,9 & 87 \\
\hline 4 & $F$ & 5 & Enlarged tonsils & 524 & 21 & 33,2 & 64 \\
\hline 5 & $\mathrm{M}$ & 7.5 & Enlarged tonsils & 409 & 15 & 12,6 & 87 \\
\hline 7 & M & 5 & $\begin{array}{l}\text { Enlarged tonsils + } \\
\text { adenoids }\end{array}$ & 404 & 20 & 42 & 66 \\
\hline 8 & M & 5.5 & Micrognathia & 463 & 10 & 41 & 82 \\
\hline 9 & $F$ & 6.5 & Enlarged tonsils & 295 & 15 & 6 & 90 \\
\hline 10 & $\mathrm{M}$ & 6.5 & Enlarged tonsils & 285 & 13 & 4,5 & 93 \\
\hline
\end{tabular}

Department of Electronics, Orsay University, Orsay, France. The different variables were monitored continuously on a 16-channel ALVAR recorder (paper speed: $15 \mathrm{~mm} / \mathrm{s}$, maximal oscillograph frequency $=70 \mathrm{~Hz}$ ).

Definitions and analyses. Sleep stages and states were scored after the criteria of Rechtschaffen and Kales international manual (10). "Phasic REM sleep" and "tonic REM sleep" were defined by presence and absence, respectively, of bursts of REM during a 20-s epoch. Arousal was defined using several criteria, including changes in EEG patterns (alpha activity and/or low voltage, mixed frequency activity) or by a "movement arousal," defined as "any increase in EMG on any channel, which is accompanied by a change in pattern on any additional channel" (10). Vincken et al. (11) have recently scored these movement arousals and indicated their frequency at the end of obstructive apneas. We require a sustained chin muscle EMG increase to last at least $2 \mathrm{~s}$ to score a movement arousal. In our prepubertal population, we considered as apnea an interruption of air exchange lasting longer than $5 \mathrm{~s}$ (12). Apnea index was defined as the number of apneas per hour of total sleep time.

In each child diaphragmatic and abdominal muscle activity was monitored supine and awake, with regular breathing for a minimum of 5 min. During nonapneic breathing in REM and NREM sleep, all breaths were analyzed for the presence or absence of abdominal muscle EMG expiratory activity. During apneic breathing in REM and NREM sleep, analysis of abdominal muscle EMG expiratory activity was also performed. The maximum peak-to-peak pen deflection recorded in the abdominal EMG channel was measured with each breath, as described by Jeffries $e t$ al. (9). In four children, muscle EMG activity was simultaneously integrated, and the maximal amplitude of the integrated signal was measured. Maximum peak-to-peak pen deflection associated with each respiratory effort was investigated during 717 NREM and REM sleep apneas. The maximal amplitude of each integrated EMG expiratory burst was simultaneously investigated in 576 of the 717 NREM and REM sleep apneas. A systematic analysis of the polygraphic changes noted with each apnea termination was also performed: presence or absence of an "EEG arousal," as well as presence or absence of a movement arousal.

\section{RESULTS}

Sleep parameters and respiratory events are presented in Table 1. Patients 9 and 10 were mainly heavy snorers with apnea indices of 6 and 4.5. Their $\mathrm{SaO}_{2}$ never fell below $90 \%$. In children 1-8 the severity of the OSAS, based on the apnea index, varied widely (11.7 to 42). They had $\mathrm{SaO}_{2}$ less than $90 \%$ in association with some apneas. The lowest $\mathrm{SaO}_{2}$, as expected, was always seen during REM sleep (Table 1).

NREM sleep. During nonapneic breathing, there was an intermittent presence of abdominal muscle EMG discharges during

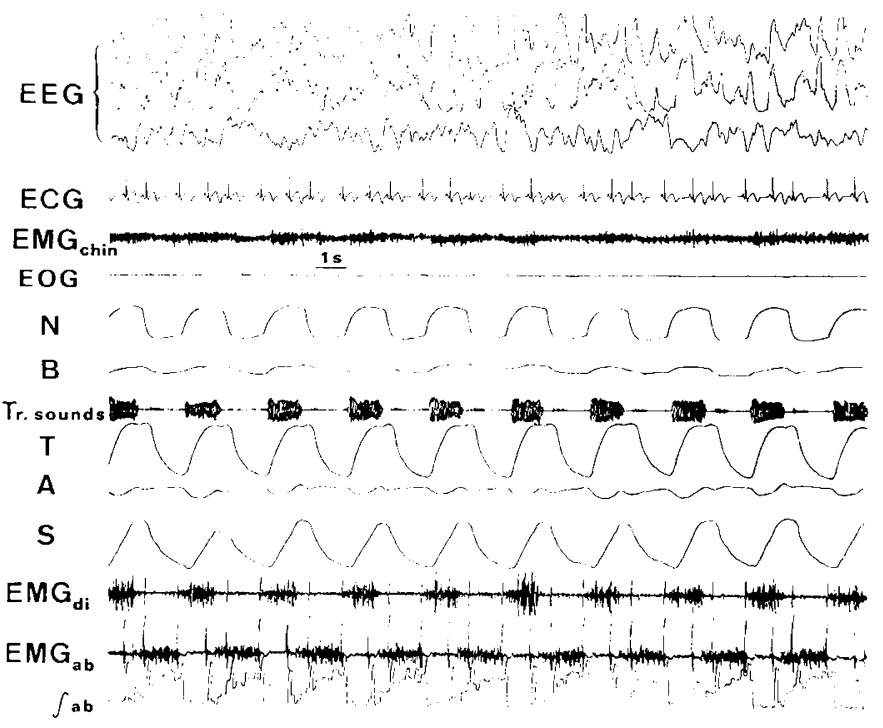

Fig. 1. Recording segment obtained during nonapneic breathing during stage 3-4 of NREM sleep in patient 7. From top to bottom: channels 1, 2, and 3, EEG: electroencephalogram; channel 4, ECG: electrocardiogram; channel 5, $E M G_{\text {chin }}$ : chin electromyogram; channel 6,EOG: electrooculogram; channel 7 and 8: nasal $(N)$ and buccal $(B)$ airflow (thermistors); channel 9, Tr sounds: tracheal sounds (microphone); channel 10,11 , and 12: thoracic $(T)$, abdominal $(A)$, and sum $(S)$ signals of the Respitrace; channel 13 and 14: diaphragmatic $\left(E M G_{a i}\right)$ and abdominal muscle $\left(E M G_{a b}\right)$ electromyogram, and channel 15 , the integrated signal from abdominal EMG ( $\left.\int a b\right)$. During stage 3-4 of NREM sleep nonapneic breathing, snoring (channel 9) is associated with abdominal EMG phasic activity at each expiration (see channels 14 and 15).

expiration concomitant with snoring. During stage 3-4 NREM sleep, which was monitored in all 10 children, snoring was consistently present and associated with abdominal muscle expiratory EMG activity during each breath (Fig. 1).

We investigated 362 NREM sleep apneas. Abdominal muscle EMG discharges were noted in all sleep stages in association with each obstructed breath. The amplitude of the EMG discharges increased from beginning to end of each NREM sleep apnea (Fig. 2). The mean increase in peak-to-peak maximum between the first and the last obstructed breath was $60 \%$ (range 30 to $100 \%$ ). The mean increase in the integrated abdominal EMG signal was $150 \%$ (range $100-500 \%$ ).

At the termination of apnea, an EEG arousal was noted in $12 \%$ of the apneic events and a movement arousal in the other $88 \%$. The maximum abdominal muscle EMG discharge was always obtained concomitant with arousal in all children (Fig. 2). 
REM sleep. During nonapneic breathing, abdominal muscle EMG discharges were absent during bursts of REM with and without snoring (Fig. 3).

We studied 355 REM sleep apneas. More than $90 \%$ of them were noted during "phasic REM sleep." All "phasic REM sleep" apneas studied were pure obstructive apneas. The REM sleep apneas studied were all associated with $\mathrm{SaO}_{2}$ decreases that oscillated between 8 and $45 \%$ (Table 1). In association with phasic REM sleep, there was no discernible pen deflection recorded in
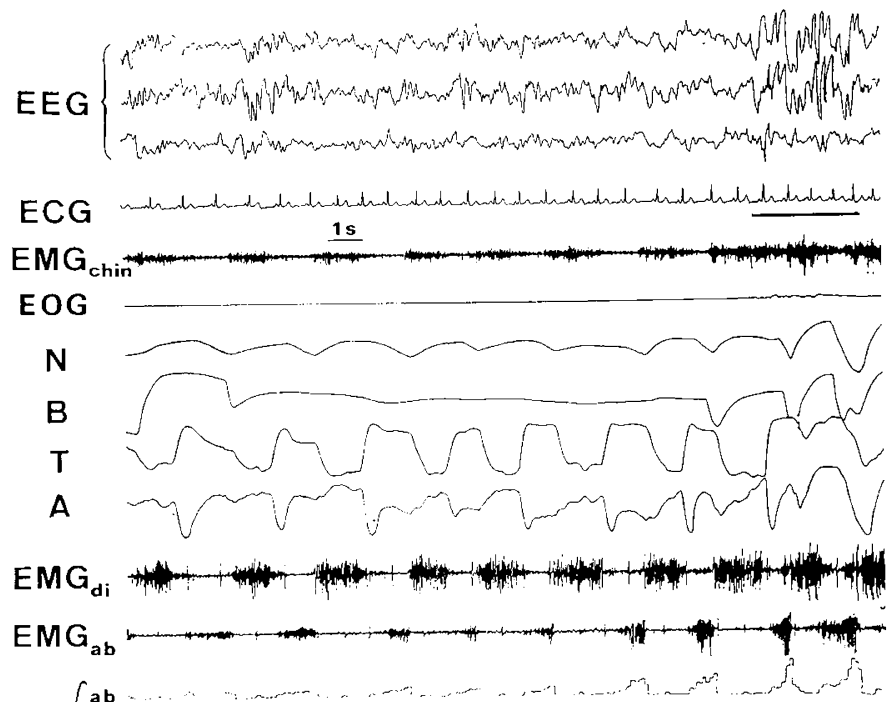

Fig. 2. Representative tracing obtained during stage 2 of NREM sleep obstructive apnea in patient 4. Channels as in Figure 1 except that for channels 9 and 10 thoracic $(T)$ and abdominal $(A)$ movements were recorded with magnetometers. During the course of stage 2 NREM-sleep obstructive apnea, the amplitude of abdominal muscle EMG phasic expiratory activity progressively increases (see channel 12 and the integrated signal on channel 13). The most important increase in maximal peak-to-peak pen deflection and in integrated abdominal muscle EMG signal is seen with the "EEG arousal" (see horizontal bar). the abdominal EMG channel during the expiratory phase of any obstructed respiratory cycle (Fig. 4). Less than $10 \%$ of the total REM sleep apneas were seen during tonic REM sleep. In some of these apneas, abdominal muscle EMG activity could be recorded during the expiratory phase of some obstructed breaths; however, no progressive increase in the amplitude of the abdominal muscle EMG activity could be noted, unlike that seen during NREM sleep apnea.

All REM sleep apneas ended with a movement arousal and not with an EEG arousal. The maximal amplitude of the quantified abdominal muscle EMG expiratory activity was always noted at the time of the arousal response, regardless of the preceding sleep state in which the apnea had appeared.

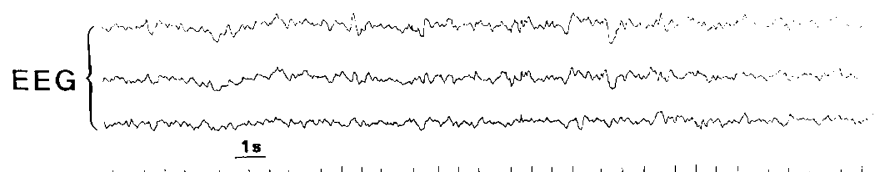

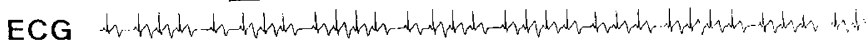
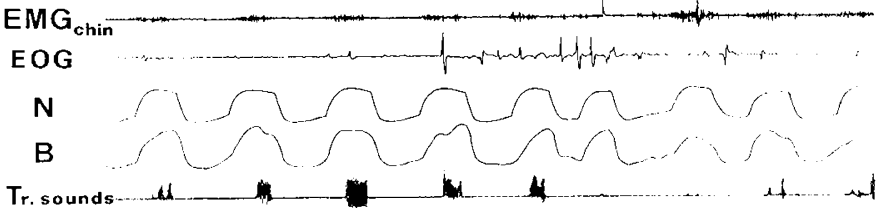
$T$

A

$\mathrm{S}$

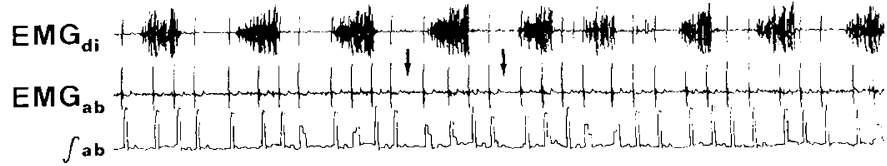

Fig. 3. Recording segment obtained during nonapneic breathing during "phasic REM sleep" in patient 7. See Figure 1 for legends. During "phasic REM sleep," the child presents with snoring (channel 9) but no abdominal EMG phasic activity during expiration (see arrows on channel 14 and the integrated signal ( $\left.\int a b\right)$ on channel 15).

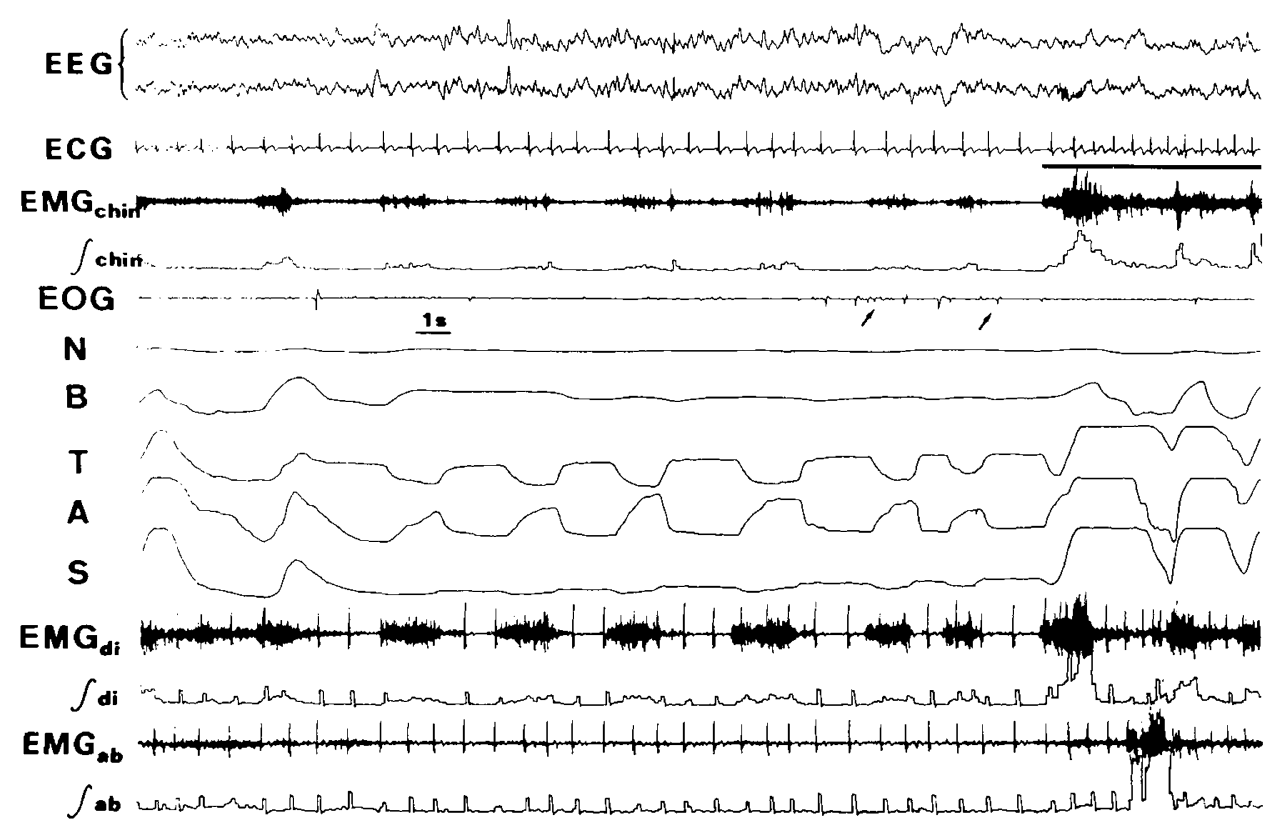

Fig. 4. Representative tracing obtained during "phasic REM sleep" (see arrows) obstructive apnea in patient 8 . See Figure 1 for legends except for channel 5 ( $\int$ chin was the integrated signal of chin EMG). During the expiratory phase of each obstructed respiratory cycle, no pen deflection (channel 14) and zero amplitude of the abdominal EMG discharge (channel 15) are seen. The apnea ends with a "movement arousal" (see horizontal bar) associated with an abdominal-muscle EMG discharge (channels 14 and 15). 


\section{DISCUSSION}

Our investigation revealed that abdominal muscle expiratory activity is present during NREM sleep in association with snoring and obstructive sleep apnea, but is absent during phasic REM sleep in partially or completely obstructed breathing in children.

Active expiration had been previously noted in snorers and OSAS patients. Schroeder et al. (13) found that OSAS patients performed not only Müller but also Valsalva maneuvers during partial or complete airway obstruction during sleep. In adult snorers, abdominal muscle expiratory activity has been shown during NREM sleep by gastric pressure measurements (4) and abdominal muscle EMG recordings $(5,6)$ Moreover, Jeffries et al. (9) previously reported that during behavioral sleep abdominal muscle EMG expiratory activity was very frequently recorded in children with OSAS, but rarely in age-matched control children without OSAS. The presence of abdominal muscle expiratory activity during NREM sleep is not very surprising. An upper airway obstruction imposes a resistive load on the respiratory muscles during both inspiration and expiration $(4,9,14)$. In adults snorers, it has been recently shown that reduction of upper airway impedance with $\mathrm{He}-\mathrm{O}_{2}(5)$ or continuous positive airway pressure (6) decreased abdominal muscle expiratory activity. Thus, our findings in prepubertal snorers and OSAS children are concordant with previous observations in adult snorers. During partial upper airway obstruction in NREM sleep, the abdominal muscle expiratory activity will tend to increase the expiratory flow and support diaphragmatic effort by placing it in a more advantageous position at the onset of the next inspiration $(7,8$, 15-17).

We have noted that during stages 3-4 NREM-sleep nonapneic breathing, heavy snoring was monitored in every polygraphic epoch. And heavy snoring during these stages 3-4 NREM was always associated with the recording of abdominal-muscle EMG discharges. This observation should be related to the report that, in adult regular snorers, there is a relationship between the NREM sleep stage progression (from stage 1 to stage $3-4$ ) and an increase in total pulmonary resistance (4).

During NREM-sleep apneic events, the progressive increase in abdominal muscle EMG discharges with each obstructed breath is in sharp contrast with the absence of abdominal muscle involvement associated with the phasic REM-sleep-related apneas. The abdominal muscle tone inhibition seen in our children in association with phasic REM sleep can be easily explained from our knowledge of REM sleep physiology: the active excitation of the bulbar inhibitory reticular formation of Magoun and Rhines (18) leads to active membrane potential hyperpolarization of spinal cord $\alpha$ - and $\gamma$-motoneurons during phasic REM sleep and abrupt muscle tone inhibition. Abdominal muscles behave like upper airway and accessory respiratory muscles during phasic REM sleep (19). The absence of "phasic-REMsleep" abdominal muscle recruitment in obstructed breathing, however, can be a handicap. As already mentioned, the favorable role that abdominal muscle contraction could have on diaphragmatic contraction $(7,8,15-17)$ or against expiratory pharyngeal flow resistive load (5) is missing during this sleep state. It reappears only with the arousal response.

Finally the arousal response was always associated with the presence of abdominal muscle contractions. These abdominal muscle EMG discharges associated with arousal were seen independent of the preceding sleep state. The arousal response, once again, appears to be the time of best adaptation to the respiratory challenge.

In summary, our findings show that the increase in abdominal muscle expiratory activity has to be considered also in the pathophysiology of OSAS in children. The well-known severity of upper airway obstruction during REM sleep could be at least in part related to the inhibition of abdominal muscle activity.

\section{REFERENCES}

1. Remmers JE, Degroot WT, Sauerland EK, Anch AM 1978 Pathogenesis of upper airway occlusion during sleep. J Appl Physiol 44:931-938

2. Guilleminault C, Hill MW, Simmons FB, Dement WC 1979 Obstructive sleep apnea: electromyographic and fiberoptic studies. Exp Neurol 62:48-67

3. Praud JP, D'Allest AM, Delaperche MF, Bobin S, Gaultier Cl 1988 Diaphragmatic and genioglossus electromyographic activity at the onset and at the end of obstructive apnea in children with obstructive sleep apnea syndrome. Pediatr Res 23:1-4

4. Skatrud JB, Dempsey JA 1985 Airway resistance and respiratory muscle function in snorers during NREM sleep. J Appl Physiol 59:328-335

5. Skatrud J, Dempsey J, Badr S, Begle R 1988 Effect of airway impedance on $\mathrm{CO}_{2}$ retention and respiratory muscle activity during NREM sleep. $\mathbf{J}$ Appl Physiol 65:1676-1685

6. Henke K, Kowitz J, Skatrud J, Dempsey J 1989 The response of inspiratory and expiratory muscles to inspiratory resistive loading during NREM sleep. FASEB J:A855

7. Önal E, Lopata M 1986 Respiratory muscle interaction during NREM sleep in patients with occlusive apnea. J Appl Physiol 61:1891-1895

8. Önal E, Lopata M, O'Connor T 1982 Pathogenesis of apneas in hypersomniasleep apnea syndrome. Am Rev Respir Dis 125:167-174

9. Jeffries B, Brouillette RT, Hunt CE 1984 Electromyographic study of some accessory muscles of respiration in children with obstructive sleep apnea. Am Rev Respir Dis 129:696-702

10. Rechtschaffen A, Kales A 1968 A manual of standardized terminology, techniques and scoring for sleep stages of human subjects. BIS, BRI, UCLA (publ. 204). NIH, Bethesda, MD

11. Vincken W, Guilleminault C, Silvestri L, Cosio M, Grassino A 1987 Inspiratory muscle activity as a trigger causing the airways to open in obstructive sleep apnea. Am Rev Respir Dis 135:372-377

12. Carskadon MA, Harvey K, Dement WC, Guilleminault C, Simmons B, Anders TF 1978 Respiration during sleep in children. West J Med 128:477-481

13. Schroeder JS, Motta J, Guilleminault C 1978 Hemodynamic studies in sleep apnea. In: Guilleminault C, Dement WC (eds) Sleep Apnea Syndromes. Alan R. Liss Inc, New York, pp 177-196

14. Anch A, Remmers J, Sauerland E, Degroot W 1981 Oropharyngeal patency during waking and sleep in the pickwickian syndrome: electromyographic activity of the tensor veli palatini. Electromyogr Neurophysiol 21:317-330

15. Martin JG, De Troyer A 1982 The behavior of the abdominal muscles during inspiratory mechanical loading. Respir Physiol 50:63-73

16. De Troyer A 1983 Mechanical action of the abdominal muscles. Bull Eur Physiopathol Respir 19:575-581

17. Issa FG, Sullivan CE 1985 Respiratory muscle activity and thoracoabdominal motion during acute episodes of asthma during sleep. Am Rev Respir Dis 132:999-1004

18. Magoun HW, Rhines R 1946 An inhibitory mechanism in the bulbar reticular formation. J Neurophysiol 9:165-171

19. Johnson MW, Remmers JE 1984 Accessory muscle activity during sleep in chronic obstructive pulmonary disease. J Appl Physiol 57:1011-1017 